\title{
ARAŞTIRMA/RESEARCH
}

\section{Ankilozan spondilit hastalarında nötrofil/lenfosit oranı, trombosit/lenfosit oranı ve ortalama trombosit hacminin değerlendirilmesi}

Evaluation of neutrophil-lymphocyte ratio, platelet-lymphocyte ratio and mean platelet volume in patients with ankylosing spondylitis

Ayhan Aşkın

İzmir Katip Çelebi Üniversitesi Atatürk Eğitim ve Araştırma Hastanesi, Fiziksel Tıp ve Rehabilitasyon Kliniği, İzmir, Turkey

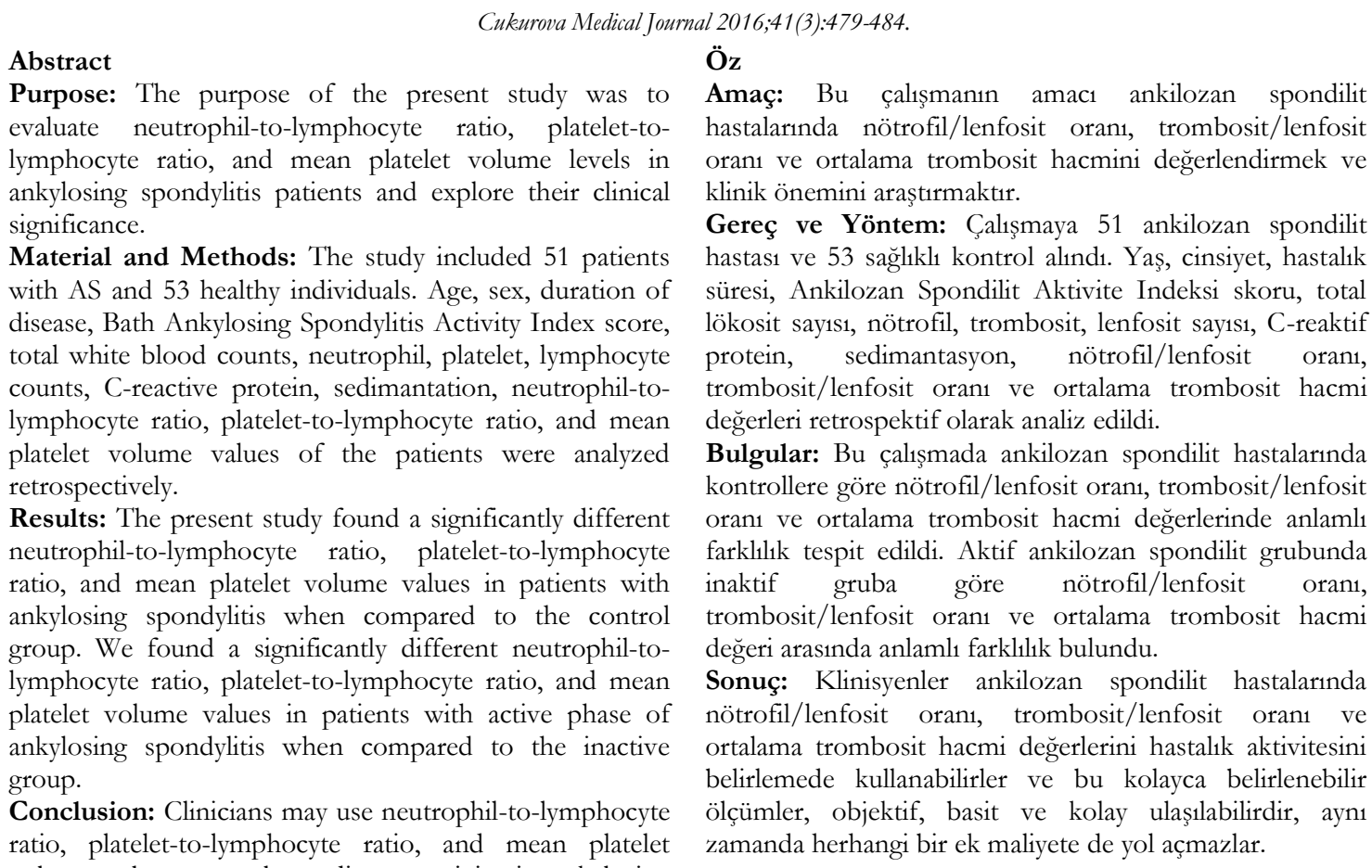
volume values to evaluate disease activity in ankylosing spondylitis since these easily determinable measurements are objective, simple and readily available and also do not lead to any additional cost.

Key words: Ankylosing spondylitis, neutrophil-tolymphocyte ratio, platelet-to-lymphocyte ratio, mean platelet volume

\section{Ö} hastalarında nötrofil/lenfosit oran1, trombosit/lenfosit oranı ve ortalama trombosit hacmini değerlendirmek ve klinik önemini araștırmaktır.

Gereç ve Yöntem: Çalışmaya 51 ankilozan spondilit hastası ve 53 sağlıklı kontrol alındı. Yas, cinsiyet, hastalık değeri restif Bulgular: Bu çalışmada ankilozan spondilit hastalarında kontrollere göre nötrofil/lenfosit oranı, trombosit/lenfosit oranı ve ortalama trombosit hacmi değerlerinde anlaml farklılık tespit edildi. Aktif ankilozan spondilit grubunda inaktif gruba göre nötrofil/lenfosit oran1, trombosit/lenfosit oranı ve ortalama trombosit hacmi değeri arasında anlamlı farklılık bulundu.

Sonuç: Klinisyenler ankilozan spondilit hastalarında nötrofil/lenfosit oranı, trombosit/lenfosit oranı ve ortalama trombosit hacmi değerlerini hastalık aktivitesin ölçümler, objektif, basit ve kolay ulaşılabilirdir, aynı zamanda herhangi bir ek maliyete de yol açmazlar.

Anahtar kelimeler: Ankilozan spondilit, nörofil/lenfosit oran1, trombosit/lenfosit oran1, ortalama trombosit hacmi 


\section{GİRİŞ}

Ankilozan spondilit (AS) etyolojisi tam olarak bilinmeyen omurga ve komşu yapıların ve daha az s1klıkla periferik eklemlerin tutulumu ile karakterize, kronik, sistemik, inflamatuvar bir hastalıktır ${ }^{1}$. Siklıkla erkeklerde ve 30'lu yaşlarda ortaya çıkar. AS'nin temel bulgusu sakroileit ve inflamatuar bel ağrisıdır. Hastalı̆̆ı kliniği asemptomatik sakroileitten deformitelerin ve ekstraartiküler bulguların eşlik ettiği şiddetli tutuluma kadar değişebilir ${ }^{1,2}$. Laboratuvar testleri hastalığın tanı ve tedavi takibinde sıklıkla kullanılmaktadır. C-reaktif protein (CRP), sedimantasyon (ESR) bu hastalarda kullanılan geçerli ve kullanımı ekonomik testlerdendir. Hastalı aktivitesi ile korelasyon gösterirler ancak aktivite değerlendirilmesinde birbirlerine üstünlükleri yoktur ${ }^{3-5}$. Diğer yandan ESR inflamasyon ile ilişkisiz olarak yaş, cinsiyet, anemi, böbrek yetmezliği gibi birçok faktörden etkilenebilir. CRP'nin inflamasyonun şiddetine göre serum düzeyinde hızla değişiklik göstermesi en önemli avantaj iken enfeksiyöz durumlarda sıklıkla karışıklıklar oluşmaktadır ${ }^{6,7}$.

Yakın zamanda birçok hastalık grubunda inflamatuvar süreçle ilişkili olan yeni belirteçler bildirilmektedir. Ortalama trombosit hacmi (MPV), nötrofil/lenfosit oranı (NLR), trombosit/lenfosit oranı (PLR) romatolojik hastalıkların takiplerinde rutin olarak istenen hemogram incelemesinden basitçe elde edilebilecek belirteçlerdir ${ }^{8-15}$. MPV hemogram parametreleri içerisinde direkt olarak yer alır. NLR ve PLR ise nötrofil veya trombosit sayılarının lenfosit sayısına bölünmesi ile çok basit bir yöntemle elde edilebilir. Romatolojik hastalıkların aktif klinik durumlarında MPV'nin azaldığ1 ve ESR, CRP ile negatif bir korelasyon gösterdiği dolasıyla negatif bir akut faz reaktanı olarak kullanılabileceği bildirilmektedir ${ }^{9,10}$. NLR ve PLR ile ilgili yayınlar farklıliklar göstermektedir. Romatoid artrit (RA) ve AS hastalarında aktif hastalıkta arttıkları bildirilse de bazı yayınlarda klinik aktivite skalalarıla korelasyon göstermediği saptanmıştır ${ }^{11}$. Gökmen ve arkadaşlar $1^{13}$. AS hastalarında NLR'nin kontrollere göre yüksek bulunduğu ve CRP ile kolere olduğunu bildirirken Boyraz ve arkadaşları16 anlamlı farklılık bulmamışlardır. PLR ise kontrollere göre anlamlı oranda düşük saptanmıştır.

$\mathrm{Bu}$ güncel veriler 1şı̆̆ında romatolojik hastalıklar polikliniğimizde takipte olan AS hastalarımızın NLR, PLR, MPV verilerini derlemeyi ve hastalık aktivite düzeyine göre sınıflayarak akut faz reaktanları ile ilişkisini saptamayı amaçladık.

\section{GEREÇ VE YÖNTEM}

Çalışma için hastanemiz Fiziksel Tip ve Rehabilitasyon Kliniğinde 2014-2016 y1lları arasında takip vizitlerine gelen AS hastalarının verileri retrospektif olarak tarandı. Çalışmaya başlamadan önce hastanemiz etik kurulundan onay alındi. Hastane yazılımının veya takip dosyalarımızın kayıtlarına göre en az 1 yıldır düzenli takiplere gelen ve AS tanısı kesinleşmiş, son 3 aydır tedavisinde değişiklik yapılmamış 51 hasta çalışmaya dahil edildi.

Verilerden diyabetes mellitus, hipertansiyon, koroner arter hastalı̆̆1, metabolik sendrom, tiroid hastalı̆̆1, kronik obstrüktif akciğer hastalığ1, astım, malignite, karaciğer veya böbrek yetmezliği, inflamatuvar barsak hastalı̆̆1, lokal ya da sistemik enfeksiyon, anemi varlığ1 saptanan hastalar çalışmaya dahil edilmedi. AS hastalarının demografik verileri (yaş, cinsiyet), hastalık süreleri ve Ankilozan Spondilit Hastalık Aktivite Indeksi (BASDAI) skoru kayıt edildi. Hastanemizde rutin laboratuvar incelemesi yapılan sağlıklı, yaş ve cinsiyet uyumlu 53 kişi kontrol grubu olarak alınd. Kontrol grubunun demografik verileri kayıt edildi.

\section{Laboratuvar}

Hasta ve kontrol grubunun laboratuvar sonuçları incelendi. Biyokimyasal analizlerden CRP $(\mathrm{mg} / \mathrm{dL})$, ESR (mm/saat) değerleri elde edildi. Hemogram incelemesinden lökosit $(\mathrm{K} / \mathrm{uL})$, nötrofil $(\mathrm{K} / \mathrm{uL})$, lenfosit $(\mathrm{K} / \mathrm{uL})$, trombosit $(\mathrm{K} / \mathrm{uL})$ sayıları ile MPV (fL) değeri alındı. NLR değeri nötrofil sayısının lenfosit sayısına bölünmesi ile PLR değeri trombosit sayısının lenfosit sayısına bölünmesi ile saptand. Laboratuvar ile klinik değerlendirme verileri hastanın aynı vizitinden yapıldı. Bir hastanın sadece bir adet vizit verisi çalışmaya alınd. Hasta ve kontrollerin verileri ile AS hastalarının BASDAI skoruna göre (BASDAI $\geq 4$ yüksek aktivite, $<4$ düşük aktivite) ayrılması ile oluşan 2 grubun verileri istatistiksel olarak karşılaştırıldı.

\section{İstatistiksel analiz}

Çalışmanın istatistiksel analizleri OSX için IBM Statistical Package for Social Sciences (SPSS) 22.0 programı kullanilarak yapildı. Hasta ve kontrollerin özelliklerinin belirlenmesinde tanımlayıcı istatistikler, hasta gruplarının karşılaştırılması Fisher kesin ki-kare 
testi, bağımsız iki örnek T testi, Mann Whitney U testi kullanıldı. Korelasyon analizi Pearson korelasyon testi ile yapıld1. İstatistiksel analizlerde $\mathrm{p}$ değerinin 0,05'ten küçük olması anlamlı olarak kabul edildi. Sonuçlar ortalama \pm standart sapma (Ort \pm SS) olarak belirtildi.

\section{BULGULAR}

Çalıșmamıza 51 hasta ve 53 sağlıklı kontrol alındı. Her iki grubun yaş ve cinsiyet dağılımı benzerdi. AS hastalarının hastalık süresi ortalamasi $7.25 \pm 5.31 \mathrm{y} 1$, BASDAI skor ortalamas1 $3.22 \pm 2.26$ idi. Grupların demografik verileri ve laboratuvar bulgularının özeti tablo 1'de gösterilmektedir. AS hastalarının lökosit, nötrofil, trombosit sayıları, CRP, NLR, PLR, MPV değerleri kontrollere göre istatistiksel anlamlı farklılık gösteriyordu ( $<<0.05$; Tablo1). Hastaların 19'unda $(\% 37,3)$ BASDAI skoru 4 değerinin üzerinde (yüksek aktivite), 32 hastada (\%62,7) ise 4’ün altında (düşük aktivite) idi. Hasta grupları arasında CRP, ESR, trombosit sayıs1, NLR, PLR, MPV değerleri istatistiksel olarak anlamlı farklılık gösteriyordu $(p<0.05)$. Hastalık aktivitesine göre gruplanan AS hastalarının demografik ve laboratuvar verilerinin karşılaştırılması Tablo2'de gösterilmektedir. Hastaların BASDAI, CRP, ESR, NLR, PLR, MPV değerleri arasındaki korelasyon analizinde NLR ile CRP arasinda istatistiksel anlamlı pozitif bir korelasyon $(\mathrm{r}=0.342, \mathrm{p}=0.014)$, PLR ile CRP arasinda pozitif korelasyon $(\mathrm{r}=0.651, \mathrm{p}<0.001)$, MPV ile CRP arasinda negatif bir korelasyon $(\mathrm{r}=$ $0.299, \mathrm{p}=0.033$ ) saptand1. PLR ile BASDAI skorlar1 arasında istatistiksel olarak anlamlı pozitif $(r=0.568$, $\mathrm{p}<0.001)$, MPV ile BASDAI arasinda negatif korelasyon $(\mathrm{r}=-0.325, \mathrm{p}=0.020)$ tespit edildi. Korelasyon analizi sonuçları Tablo 3'de görülmektedir.

Tablo 1. Çalışma gruplarının demografik verileri ve laboratuvar bulguları

\begin{tabular}{|l|c|c|c|}
\hline & $\begin{array}{c}\text { AS } \\
(\mathbf{n = 5 1 )}\end{array}$ & $\begin{array}{c}\text { Kontrol } \\
(\mathbf{n}=\mathbf{5 3})\end{array}$ & $\mathbf{p}$ \\
\hline Yaş (yl) & $40.82 \pm 8.96$ & $40.16 \pm 12.11$ & 0.756 \\
\hline Cinsiyet (K/E) N & $2 / 49$ & $4 / 49$ & $0.67 *$ \\
\hline Hastalı süresi (y1l) & $7.25 \pm 5.31$ & - & \\
\hline BASDAI (0-10) & $3.22 \pm 2.26$ & - & $<\mathbf{0 . 0 0 1}$ \\
\hline CRP (mg/dL) & $1.07 \pm 1.40$ & $0.25 \pm 0.24$ & 0.543 \\
\hline ESR (mm/saat) & $17.25 \pm 15.84$ & $15.69 \pm 9.47$ & $\mathbf{0 . 0 0 3}$ \\
\hline Lökosit (K/uL) & $7.93 \pm 2.06$ & $6.84 \pm 1.48$ & $<\mathbf{0 . 0 0 1}$ \\
\hline Nötrofil $(\mathrm{K} / \mathrm{uL})$ & $5.03 \pm 1.76$ & $3.96 \pm 1.16$ & 0.406 \\
\hline Lenfosit $(\mathrm{K} / \mathrm{uL})$ & $2.27 \pm 0.82$ & $2.15 \pm 0.56$ & $<\mathbf{0 . 0 0 1}$ \\
\hline Trombosit $(\mathrm{K} / \mathrm{uL})$ & $303843.13 \pm 74844.47$ & $248849.05 \pm 45370.43$ & $\mathbf{0 . 0 2 8}$ \\
\hline NLR & $2.45 \pm 1.12$ & $2.00 \pm 0.94$ & $\mathbf{0 . 0 0 9}$ \\
\hline PLR & $153543.30 \pm 75467.21$ & $122107.66 \pm 39681.20$ & $<\mathbf{0 . 0 0 1}$ \\
\hline MPV (fL) & $9.44 \pm 0.84$ & $10.42 \pm 1.01$ & \\
\hline
\end{tabular}

AS:Ankilozan Spondilit, BASDAI:Ankilozan Spondilit Hastalık Aktivite İndeksi, ESR:sedimantasyon, CRP:C-reaktif protein, NLR:nötrofil/lenfosit oranı, PLR:trombosit/lenfosit oranı, MPV:ortalama trombosit hacmi; Bağımsız iki örnek T testi * Fisher kesin ki-kare testi

\section{TARTIŞMA}

Çalışmamızda AS hastalarında kontrollere göre ve ayrıca hastalık aktivitesi yüksek olanlarda düşük olanlara göre NLR ve PLR değerlerini yüksek, MPV değerlerini ise düşük olarak saptadık. Hastalık aktivite skoru ile PLR değerleri pozitif, MPV değerleri negatif korelasyon gösteriyordu.

Yakın zamanda NLR ve PLR değerleri maligniteler, diyabetes mellitus, koroner arter hastalığ1, inflamatuvar romatizmal hastaliklarda sistemik inflamatuvar yanıt ile ilişkilendirilmiştir'12,17-20. Hemogram sonucundan kolaylikla ek bir ekonomik yük getirmeden elde edilebilmeleri önemli avantajlarıdır ve bu nedenle kullanımları yaygınlaşmaktadır. Sistemik inflamasyonda dolaşımdaki lenfosit sayısında azalma, nötrofili ve trombositoz meydana gelir. Nötrofili apopitozis gecikmesi, nötrofillerin demarjinasyonu ve büyüme faktörleri aracılığı ile kök hücrelerin stimülasyonu ile oluşur. Bu açıdan bakıldığında nötrofiller uzamış inflamasyondan sorumlu iken lenfositler düzenleyici fonksiyon gösterirler. Böylece kronik inflamasyonda NLR ve PLR'nin arttığ1 görülebilmektedir ${ }^{21}$. Bu belirteçlerin sistemik inflamasyonun ön planda olduğu birçok romatizmal hastalıkta da hastalık aktivitesi ile ilișkisi araștırılmıștır. 
Tablo 2. Hastaların hastalık aktivite indeksine (BASDAI) göre karşılaştırılması

\begin{tabular}{|l|c|c|c|}
\hline & $\begin{array}{c}\text { Yüksek aktivite } \\
\text { BASDAI } \mathbf{4} \\
\mathbf{n = 1 9}\end{array}$ & $\begin{array}{c}\text { Düşük aktivite } \\
\text { BASDAI } \\
\mathbf{n = 3 2}\end{array}$ & $\mathbf{p}$ \\
\hline Yaş (yll) & $41.47 \pm 10.30$ & $40.43 \pm 8.21$ & 0.694 \\
\hline Cinsiyet (K/E) N & $2 / 17$ & $0 / 32$ & $0.13^{*}$ \\
\hline Hastalık süresi (yll) & $8.57 \pm 4.18$ & $6.46 \pm 5.80$ & 0.173 \\
\hline CRP (mg/dL) & $2.30 \pm 1.68$ & $0.34 \pm 0.25$ & $<\mathbf{0 . 0 0 1}$ \\
\hline ESR(mm/saat) & $31.31 \pm 17.42$ & $8.90 \pm 5.95$ & $<0.001$ \\
\hline Lökosit (K/uL) & $7.68 \pm 2.06$ & $8.08 \pm 2.07$ & 0.505 \\
\hline Nötrofil (K/uL) & $5.24 \pm 1.57$ & $4.91 \pm 1.88$ & 0.520 \\
\hline Lenfosit (K/uL) & $1.99 \pm 0.73$ & $2.44 \pm 0.84$ & 0.060 \\
\hline Trombosit (K/uL) & $378789.47 \pm 46447.79$ & $259343.75 \pm 47912.29$ & $<\mathbf{0 . 0 0 1}$ \\
\hline NLR & $2.80 \pm 0.93$ & $2.24 \pm 1.81$ & $\mathbf{0 . 0 0 8}$ \\
\hline PLR & $213829.04 \pm 80080.09$ & $117748.64 \pm 43729.73$ & $<\mathbf{0 . 0 0 1}$ \\
\hline MPV (fL) & $9.02 \pm 0.75$ & $9.70 \pm 0.80$ & $\mathbf{0 . 0 0 5}$ \\
\hline
\end{tabular}

BASDAI:Ankilozan Spondilit Hastalık Aktivite İndeksi, ESR:sedimantasyon, CRP:C-reaktif protein, NLR:nötrofil/lenfosit oran1, PLR:trombosit/lenfosit oran1, MPV:ortalama trombosit hacmi

Mann Whitney U testi $\quad *$ Fisher kesin ki-kare testi

Tablo 3. AS hastalarında klinik ve laboratuvar parametrelerin korelasyon değerlendirmeleri

\begin{tabular}{|c|c|c|c|c|c|}
\hline & CRP & ESR & BASDAI & NLR & PLR \\
\hline CRP & $\begin{array}{c}1.000 \\
-\end{array}$ & - & - & - & - \\
\hline ESR & $\begin{array}{c}r=0.795 \\
(p<0.001)\end{array}$ & $\begin{array}{c}1.000 \\
-\end{array}$ & - & - & - \\
\hline BASDAI & $\begin{array}{c}r=0.731 \\
(\mathrm{p}<0.001)\end{array}$ & $\begin{array}{c}r=0.689 \\
(\mathrm{p}<0.001)\end{array}$ & $\begin{array}{c}1.000 \\
-\end{array}$ & - & - \\
\hline NLR & $\begin{aligned} r & =0.342 \\
(p & =0.014)\end{aligned}$ & $\begin{aligned} r & =0.210 \\
(p & =0.138)\end{aligned}$ & $\begin{aligned} r & =0.260 \\
(p & =0.065)\end{aligned}$ & $\begin{array}{c}1.000 \\
-\end{array}$ & - \\
\hline PLR & $\begin{array}{c}r=0.651 \\
(\mathrm{p}<0.001)\end{array}$ & $\begin{array}{c}r=0.576 \\
(\mathrm{p}<0.001)\end{array}$ & $\begin{array}{c}r=0.568 \\
(\mathrm{p}<0.001)\end{array}$ & $\begin{array}{c}r=0.528 \\
(p<0.001)\end{array}$ & $\begin{array}{c}1.000 \\
-\end{array}$ \\
\hline MPV & $\begin{array}{l}r=-0.299 \\
(p=0.033)\end{array}$ & $\begin{array}{l}r=-0.309 \\
(p=0.027)\end{array}$ & $\begin{array}{l}r=-0.325 \\
(p=0.020)\end{array}$ & $\begin{array}{l}\mathrm{r}=-0.289 \\
(\mathrm{p}=0.039)\end{array}$ & $\begin{array}{l}r=-0.024 \\
(p=0.113)\end{array}$ \\
\hline
\end{tabular}

AS: Ankilozan spondility, BASDAI:Ankilozan Spondilit Hastalık Aktivite Indeksi, ESR:sedimantasyon, CRP:C-reaktif protein, NLR:nötrofil/lenfosit oran1, PLR:trombosit/lenfosit oranı, MPV:ortalama trombosit hacmi; Pearson Korelasyon Analizi

Mercan ve arkadaşlar1 ${ }^{11}$ RA ve AS hasta gruplarında kontrollere göre NLR değerlerini yüksek, ESR ve CRP ile kolere, DAS28 skorları ile uyumlu bulmuşlar ancak BASDAI ile ilişki saptamamışlardır. Uslu ve arkadaşlar1 $^{12}$ RA hastalarında NLR ve PLR değerlerini hastalık aktivitesinin değerlendirilmesinde kullanılabileceğini bildirmişlerdir. Gökmen ve arkadașları ${ }^{13}$ AS hastalarında kontrol grubuna göre NLR değerlerini yüksek tespit etmişler ve inflamasyonun gösterilmesinde CRP gibi diğer akut faz reaktanlarıyla birlikte kullanılabileceğini bildirmişlerdir.

Fu ve arkadaşlar1 ${ }^{14} 2015$ yılında yaptıkları bir çalıșmada hem NLR hem PLR' nin DAS28 ile kolere olduğunu ve bu belirteçlerin RA hastalarında hastalık aktivitesini değerlendirmede kullanılabileceğini göstermișlerdir. Çoşkun ve arkadaşaları $^{22}$. AS hastalarında kontrollere göre NLR değerlerini yüksek bulmuşlar ve NLR değerinin bu hasta grubunun takiplerinde kullanılabilecek kolay ulaşılabilen geçerli bir metod olduğunu bildirmişlerdir. NLR ve PLR'nin sistemik lupus eritamatozus, ailevi akdeniz ateşi, Behçet hastalığ1, psöriatik artrit hastalı gruplarında da kullanılabilecek bir inflamatuvar marker olabileceği bildirilmektedir ${ }^{23-26}$.

Çalışmamızda AS hastalarında CRP, nötrofil sayısı, trombosit, NLR, PLR değerlerini kontrol grubuna göre anlamlı şekilde yüksek saptadık. Ayrıca hastalık aktivitesi yüksek grupta NLR ve PLR değerleri daha yüksekti ve PLR değerleri BASDAI skoruyla pozitif bir korelasyon gösterdi. Elde ettiğimiz veriler 
literatürdeki verilerle benzer olarak AS hastalarında hastalık aktivasyonunun gösterilmesinde NLR ve PLR'nin faydalı olabileceğini desteklemektedir. PLR bu anlamda BASDAI skoru, CRP, ESR, NLR ile orta derecede korelasyon göstermesi nedeniyle çalışmamızda NLR'ye göre daha anlamlı bulunmuştur.

Aktif inflamasyonda trombosit sayısında artış beklenen bir durumdur. Rutin hemogram parametresi olarak çalışılan MPV'nin, trombosit fonksiyonu ve aktivasyonu ile korelasyonu kanıtlanmıştır ${ }^{27}$. Literatürde MPV'nin inflamatuvar aktivite ile pozitif ya da negatif korelasyon gösterdiğini bildiren farklı çalışmalar bulunmaktadır. Yazıcı ve arkadaşları ${ }^{28}$ AS ve RA hastalarında MPV değerlerini yüksek bulmuşlar ve hastalık aktivitesi ile ilişkilendirmişlerdir.

Güneş ve arkadaşları ${ }^{29}$ aktif juvenil idiopatik artrit hastalık grubunda MPV değerlerini kontrollere ve inaktif hasta grubuna göre yüksek saptamışlardır. Farklı olarak Şahin ve arkadaşları ${ }^{10} .2015$ yıllndaki yayınlarında düşük MPV düzeylerinin aktif veya kronik inflamatuvar durum ile ilişkili olduğunu bildirmişlerdir. Zareifar ve arkadaşlar ${ }^{30}$ yüksek trombosit sayısı ve düşük MPV değerlerini aktif inflamatuvar durumla ilişkilendirmiştir. Çalışmamızda Şahin ve Zareifar'ın sonuçlarına benzer şekilde, hem AS hastalarında kontrollere göre hem de aktif hastalık grubunda düşük aktivite grubuna göre trombosit sayısını yüksek ve MPV değerlerini düşük saptadık. Ayrıca BASDAI skoru ile MPV zayıf negatif bir korelasyon gösteriyordu. MPV değerlerinin aktif hastalıkta düşük bulunması trombositlerin inflamasyon bölgesinde tüketilmesi, megakaryopoezin uyarılması ve küçük hacimli trombositlerin salınması ile ilişkili olduğu bildirilmektedir ${ }^{27}$. Çalışmamızın bazı kısıtlılıkları mevcuttur. Öncelikle prospektif yerine retrospektif değerlendirme yapılması önemli bir kısıtl1l1ktır. Ayrica hasta ve kontrol grubundaki katilımc1 sayıs da azdır. Retrospektif analiz nedeniyle klinik verilere kısıtlı ulaşabilmemiz NLR, PLR, MPV değerlerinin takiplerde tedavi ile değişimini izlememize imkan vermemiştir.

Sonuç olarak AS hastalarında NLR, PLR ve MPV hastalık aktivitesinin saptanmasında kullanılabilecek basit, kolay ulaşılabilir belirteçler olarak görülmektedir. Ancak bu konuda daha fazla hasta sayısı ve klinik değerlendirme parametreleri ile yapılacak çalışmalara gereksinim vardır.

\section{KAYNAKLAR}

1. Braun J, Sieper J. Ankylosing spondylitis. Lancet. 2007;369:1379-90.

2. Dougados M, Baeten D. Spondyloarthritis. Lancet. 2011;377:2127-37.

3. Spoorenberg A, van der Heijde D, de Klerk E, Dougados M, de Vlam K, Mielants H et al. Relative value of erythrocyte sedimentation rate and Creactive protein in assessment of disease activity in ankylosing spondylitis. J Rheumatol. 1999;26:980e4.

4. de Vries MK, van Eijk IC, van der Horst-Bruinsma IE, Peters MJ, Nurmohamed MT, Dijkmans BA et al. Erythrocyte sedimentation rate, C-reactive protein level, and serum amyloid a protein for patient selection and monitoring of anti-tumor necrosis factor treatment in ankylosing spondylitis. Arthritis Rheum. 2009;61:1484-90.

5. Dernis E, Lavie F, Pavy S, Wendling D, Flipo RM, Saraux A et al. Clinical and laboratory follow-up for treating and monitoring patients with ankylosing spondylitis: development of recommendations for clinical practice based on published evidence and expert opinion. Joint Bone Spine. 2007;74:330-7.

6. Colglazier CL, Sutej PG. Laboratory testing in the rheumatic diseases: a practical review. South Med J. 2005;98:185-91.

7. Waits JB. Rational use of laboratory testing in the initial evaluation of soft tissue and joint complaints. Prim Care. 2010;37:673-89.

8. Gasparyan AY, Ayvazyan L, Mikhailidis DP, Kitas GD. Mean platelet volume: a link between thrombosis and inflammation? Curr Pharm Des. 2011;17:47-58.

9. Zareifar S, Farahmand Far MR, Golfeshan F, Cohan $\mathrm{N}$. Changes in platelet count and mean platelet volume during infectious and inflammatory disease and their correlation with ESR and CRP. J Clin Lab Anal. 2014;28:245-8.

10. Şahin A, Yetişgin A, Şahin M, Durmaz Y, Cengiz AK. Can mean platelet volume be a surrogate marker of inflammation in rheumatic diseases? West Indian Med J 2015; doi: 10.7727/wimj.2014.202.

11. Mercan R, Bitik B, Tufan A, Bozbulut UB, Atas N, Ozturk MA et al. The association between neutrophil/lymphocyte ratio and disease activity in rheumatoid arthritis and ankylosing spondylitis. J Clin Lab Anal. 2015; doi: 10.1002/jcla.21908.

12. Uslu AU, Küçük A, Şahin A, Ugan Y, Yllmaz R, Güngör $T$ et al. Two new inflammatory markers associated with Disease Activity Score-28 in patients with rheumatoid arthritis: neutrophil-lymphocyte ratio and platelet-lymphocyte ratio. Int J Rheum Dis. 2015;18:731-5.

13. Gökmen F, Akbal A, Reşorlu H, Gökmen E, Güven $\mathrm{M}$, Aras $\mathrm{AB}$ et al. Neutrophil-lymphocyte ratio connected to treatment options and inflammation 
markers of ankylosing spondylitis. J Clin Lab Anal. 2015;29:294-8

14. Fu H, Qin B, Hu Z, Ma N, Yang M, Wei $T$ et al. Neutrophil-and platelet-to-lymphocyte ratios are correlated with disease activity in rheumatoid arthritis. Clin Lab. 2015;61:269-73.

15. Qin B, Ma N, Tang Q, Wei T, Yang M, Fu H et al. Neutrophil to lymphocyte ratio (NLR), platelet to lymphocyte ratio (PLR) were useful markers in assessment of inflammatory response and disease activity in SLE patients. Mod Rheumatol. 2015;25:116.

16. Boyraz I, Koç B, Boyacı A, Tutoğlu A, Sarman H, Ozkan H. Ratio of neutrophil/lymphocyte and platelet/lymphocyte in patient with ankylosing spondylitis that are treating with anti-TNF. Int J Clin Exp Med. 2014;15:2912-5.

17. Templeton AJ, Ace O, McNamara MG, Al-Mubarak M, Vera-Badillo FE, Hermanns T et al. Prognostic role of platelet to lymphocyte ratio in solid tumors: a systematic review and meta-analysis. Cancer Epidemiol Biomarkers Prev. 2014;23:1204-12.

18. Xin-Ji Z, Yong-Gang L, Xiao-Jun S, Xiao-Wu C, Dong Z, Da-jian Z. The prognostic role of neutrophils to lymphocytes ratio and platelet count in gastric cancer: A meta-analysis. Int J Surg. 2015;21:84-91.

19. Verdoia M, Schaffer A, Barbieri L, Aimaretti G, Marino P, Sinigaglia F. Impact of diabetes on neutrophil-to-lymphocyte ratio and its relationship to coronary artery disease. Diabetes Metab. 2015;41:304-11.

20. Sari I, Sunbul M1, Mammadov C, Durmus E, Bozbay M, Kivrak T et al. Relation of neutrophil-tolymphocyte and platelet-to-lymphocyte ratio with coronary artery disease severity in patients undergoing coronary angiography. Kardiol Pol. 2015;73:1310-6

21. Zahorec R. Ratio of neutrophil to lymphocyte counts-rapid and simple parameter of systemic inflammation and stress in critically ill. Bratisl Lek Listy. 2001;102:5-14.

22. Çoşkun BN, Öksüz MF, Ermurat S, Tufan AN, Oruçoğlu N, Doğan A et al. Neutrophil lymphocyte ratio can be a valuable marker indefining disease activity in patients who have started anti tumor necrosis factor (TNF) drugs for ankylosing spondylitis. Eur J Rheumatol. 2014;1:101-5.

23. Wu Y, Chen Y, Yang X, Chen L, Yang Y. Neutrophil-to-lymphocyte ratio (NLR) and plateletto-lymphocyte ratio (PLR) were associated with disease activity in patients with systemic lupus erythematosus. Int Immunopharmacol. 2016; 36:949 .

24. Uluca Ü, Ece A, Șen V, Karabel D, Yel S, Güneş A et al. Usefulness of mean platelet volume and neutrophil-to-lymphocyte ratio for evaluation of children with familial mediterranean fever. Med Sci Monit. 2014;20:1578-82.

25. Alan S, Tuna S, Türkoğlu EB. The relation of neutrophil-to-lymphocyte ratio, platelet-tolymphocyte ratio, and mean platelet volume with the presence and severity of Behçet's syndrome. Kaohsiung J Med Sci. 2015;31:626-31.

26. Kim DS, Shin D, Lee MS, Kim HJ, Kim DY, Kim SM. Assessments of neutrophil to lymphocyte ratio and platelet to lymphocyte ratio in Korean patients with psoriasis vulgaris and psoriatic arthritis. J Dermatol. 2016;43:305-10.

27. Bath PM, Butterworth RJ. Platelet size: measurement, physiology and vascular disease. Blood Coagul Fibrinolysis. 1996;7:157-61.

28. Yazici S, Yazici M, Erer B, Erer B, Calik Y, Bulur S et al. The platelet functions in patients with ankylosing spondylitis, anti- TNF-alpha therapy decreases the mean platelet volume and platelet mass. Platelets. 2010;21:126e31.

29. Güneș A, Ece A, Șen V, Uluca Ü, Aktar F, Tan İ. Correlation of mean platelet volume, neutrophil-tolymphocyte ratio, and disease activity in children with juvenile 1diopathic arthritis. Int J Clin Exp Med. 2015;8:11337-41.

30. Zareifar S, Farahmand Far MR, Golfeshan F, Cohan $\mathrm{N}$. Changes in platelet count and mean platelet volume during infectious and inflammatory disease and their correlation with ESR and CRP. J Clin Lab Anal. 2014;28:245-8. 